International

Medical Society

http://imedicalsociety.org

\title{
Bowel Injury following Liposuction. A rare Complication of Cosmetic Surgery

\section{Abstract}

Liposuction is one of the most commonly performed surgical procedures for aesthetic reasons. It is often performed as day-case surgery and is thought to be a low-risk 'minor' procedure. We present a rare case of necrotising abdominal wall infection due to small bowel injury resulting in extensive abdominal wall debridement and the development of an enteric fistula.

\section{Case presentation}

Mr G is 56-year-old previously fit and well male that presented to our institution following liposuction surgery performed under general anaesthesia at another private hospital. His liposuction surgery was initially planned as a day-case procedure however due to post operative discomfort Mr G stayed overnight in hospital.

Mr $\mathrm{G}$ presented to our emergency department 6 days after the procedure with significant abdominal pain and bloating. He had a septic presentation with marked abdominal wall erythema, a temperature of 38.4 degrees Celsius and tachycardia (pulse 120/min). Examination of his abdomen revealed widespread crepitus.

\section{Investigations}

Biochemical investigations demonstrated a white cell count of 14.2 x109/L and C-reactive protein of 396mg/l. Haemoglobin, coagulation and renal function studies were normal. An erect chest X-ray demonstrated free intra-peritoneal air.

\section{Treatment}

Mr G was resuscitated with intravenous fluid and commenced on broad spectrum antibiotics. He was then taken to the acute operating theatre. Exploration of his abdomen confirmed necrotising infection of the abdominal wall and widespread bile staining. Figure 1 demonstrates the wide extent of undermined tissue as a result of the necrotising infection and a fascia puncture site can be seen.

\author{
Amit Kumar Reddy ${ }^{1}$
}

1 Research Fellow, Department of surgery and anaesthesia, University on Otago, Wellington.

\section{Contact information:}

Amit Kumar Reddy.

”amit_reddy1@hotmail.com

\section{Keywords}

Liposuction; Complications; Enterocutaneous Fistula. 
Figure 1: Intra-operative photograph demonstrating fascia puncture site.

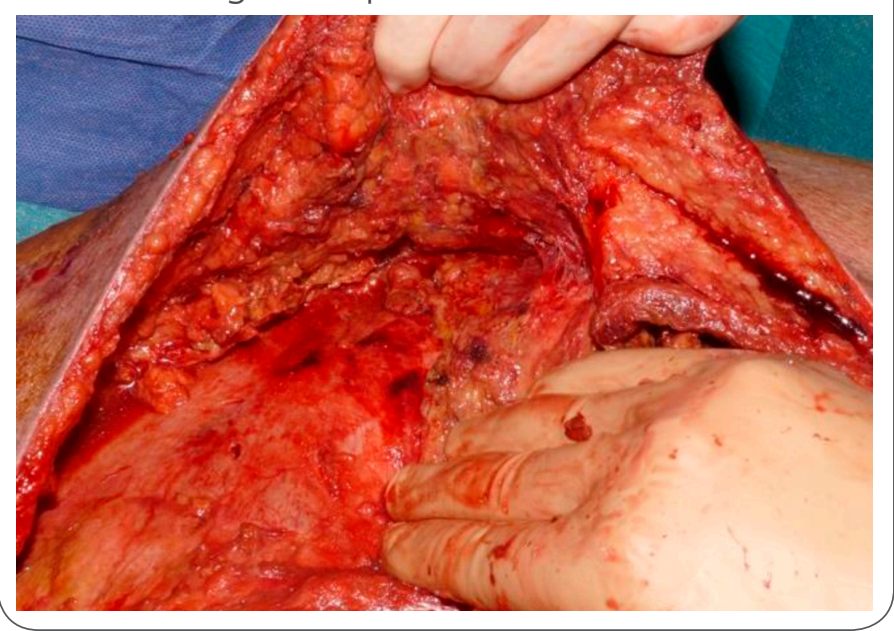

The procedure progressed to a laparotomy which found several puncture sites in the small bowel. A 'damage-control' strategy was undertaken with the injured small bowel resected using a gastro-intestinal stapler and formation of a temporary abdominal closure. Mr G was taken to ICU intubated for further resuscitation. The following day $\mathrm{Mr} \mathrm{G}$ returned to theatre for repeat assessment of his abdomen. A further debridement was undertaken and a stapled small bowel anastomosis was performed to restore gastro-intestinal continuity. His abdominal fascia was able to be closed however due to the large amount of soft tissue loss a negative-pressure dressing was applied.

\section{Outcome and follow-up}

Mr G was managed with serial dressing changes, however unfortunately he developed an enteric fistula at the superior aspect of his wound. This was controlled with stoma therapy involvement, nil by mouth and parenteral nutrition. The fistula eventually matured to a spouting stoma seen in Figure 2. Six months following the initial injury Mr G underwent a further laparotomy and resection of his fistula. This proved very straightforward and after an uneventful 7-day post operative course Mr G was discharged home.
Figure 2: Clinical photograph 5 months following injury demonstrating superficial enteric fistula.

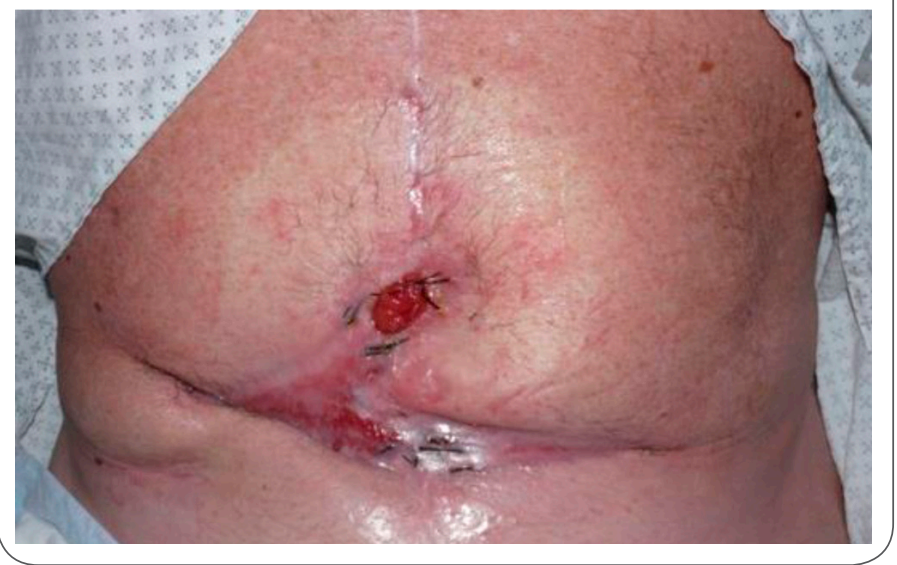

\section{Discussion}

This case highlights a number of important learning points. Liposuction is a procedure that is performed for cosmetic reasons on typically healthy individuals. Liposuction is associated with a low complication rate and patient satisfaction following the procedure is high [1]. Many complications relate to the ultimate cosmetic appearance however there are potentially life threatening complications. These include pulmonary embolism, abdominal fascia penetration, thoracic penetration, cardiorespiratory failure, lidocaine toxicity and haemorrhage [2-4].

Bowel injury following liposuction is rare and has only been reported in 12 case reports [5]. The actual incidence is not truly known as all of the current literature is based on case reports, questionaries and surveys $[2,6]$ and therefore subject to reporting bias. The morbidity associated with bowel injury is varied however it also carries significant mortality. A survey conducted by Grazer et al. found that visceral perforation was responsible for $14.6 \%$ of fatal outcomes following liposuction [2]. Here we have presented the first published case of the development of an enteric fistula which led to a prolonged period of medical and surgical management and significant morbidity.

Our case demonstrates the consistent theme of delayed diagnosis $[7,8]$. As with other reports $\mathrm{Mr}$ $\mathrm{G}$ had early symptoms of abdominal pain, this was 
so severe that it led to an overnight admission for what was meant to be a day-case procedure. This should have prompted early concern. Mr G was a healthy individual with no comorbidities which likely accounted for the lack of initial physiological derangement. By the time he presented to our emergency department almost one week after his liposuction he had clear features of sepsis.

The delay to surgery from initial injury led to marked peritonitis with significant bowel oedema. Despite the measures of 'damage control' principles $\mathrm{Mr} \mathrm{G}$ developed an enteric fistula which lead to prolonged hospitalisation. The fistula may have resulted from an unrecognised small bowel injury or the result of a leak from the small bowel anastomosis performed at the re-look laparotomy.

Risk factors for intestinal penetration have been described and include abdominal hernias, rectus divarication, previous abdominal surgery, and obesity [9]. This case demonstrates that injury may still occur in patients without these higher risk features. A low index of suspicion is required in the assessment of abdominal pain following liposuction and the diagnosis may be made on a simple erect chest $\mathrm{x}$-ray, as was the case in our patient. Early diagnosis and surgical management may have led to reduced morbidity.

\section{Learning points}

- Abdominal pain following liposuction out of proportion to the level expected should prompt further investigation.

- Systemic signs of sepsis may not be present until late in healthy patients and so their absence should not exclude the need for further investigations.

- The early identification and treatment of bowel injury may limit the morbidity of the initial injury.

- At laparotomy for fascia penetration a careful inspection of all abdominal contents is required to be sure that no injuries are missed.

\section{Acknowledgements}

We would like to acknowledge Louise Goossens, medical photographer for taking the clinical photographs.

\section{Competing and Conflicting Interests}

Amit Kumar Reddy has no conflicts of interest to declare.

\section{References}

1. Masoumi Lari SJ, Roustaei N, Roshan SK, Chalian M, Chalian $\mathrm{H}$, Honarbakhsh Y. Determinants of patient satisfaction with ultrasound assisted liposuction. Aesthet Surg J. 2010; 30: 714-9.

2. Grazer FM, de Jong RH. Fatal outcomes from liposuction: census survey of cosmetic surgeons. Plast Reconstr Surg. 2000; 105(1): 436-46.

3. Dixit V, Wagh MS. Unfavourable outcomes of liposuction and their management. Indian J Plast Surg. 2013; 46(2): 377-392. http://www.ijps.org/text.asp?2013/46/2/377/118617

4. Rama B, Rao RB, Ely SF, Hoffman RS. Deaths related to liposuction. N Engl J Med. 1999; 340: 1471-5.

5. Delliere V, Bertheuil, Harnois Y, Thienot S, Gerard M, Robert $M$, et al. Multiple bowel perforation and necrotizing fasciitis secondary to abdominal liposuction in a patient with bilateral lumbar hernia. Indian J Plast Surg. 2014; 47(3): 436-440. http://www.ijps.org/text.asp?2014/47/3/436/146650

6. Lehnhardt M, Homann HH, Daigeler A, Hauser J, Palka P, Steinau HU. Major and lethal complications of liposuction: A review of 72 cases in Germany between 1998 and 2002. Plastic Reconstr Surg. 2008; 121(6): 396e-403e.

7. Sharma D, Dalencourt G, Bitterly T, Benotti PN. Small intestinal perforation and necrotizing fasciitis after abdominal liposuction. Aesthetic Plast Surg. 2006; 30(6): 712-716

8. Talmor M, Hoffman LA, Lieberman M. Intestinal perforation after suction lipoplasty: A case report and review of the literature. Ann Plast Surg. 1997; 38(2): 169-172.

9. Di Candia M, Malata CM. Aesthetic and functional abdominal wall reconstruction after multiple bowel perforations secondary to liposuction. Aesthetic Plast Surg. 2011; 35(2): 274-7.

\section{Publish in International Archives of Medicine}

International Archives of Medicine is an open access journal publishing articles encompassing all aspects of medical science and clinical practice. IAM is considered a megajournal with independent sections on all areas of medicine. IAM is a really international journal with authors and board members from all around the world. The journal is widely indexed and classified Q1 in category Medicine. 